\title{
MUDANÇAS DE PODER NA CASA DE FORÇAS: EUROPA, EDUCAÇÃO SUPERIOR E ONDAS SÍSMICAS DE DESLOCAMENTOS
}

\author{
SUSAN L. ROBERTSON \\ University of Cambridge, Cambridge, Reino Unido \\ MÁrio Luiz Neves de AzeVedo \\ Universidade Estadual de Maringá, Maringá (UEM), Paraná, Brasil \\ Afrânio Mendes Catani \\ Universidade de São Paulo (USP), São Paulo, SP, Brasil \\ TRADUTORES
}

\begin{abstract}
Resumo: Este artigo tem por objetivo analisar as dinâmicas de mudanças de poder, inclusive a causada pelo processo de Brexit a partir do referendo de 2016, e suas conseqüências sociais, políticas e econômicas na sociedade e na educação superior no Reino Unido e na Europa.
\end{abstract}

\section{RUPTURAS}

Em uma postagem de blog escrita nos dias que se seguiram ao resultado do referendo de junho de 2016 no Reino Unido - a respeito de 'permanecer' ou 'deixar' a União Europeia (EU) - escrevi: "... de alguma forma, a Terra parece ter mudado de curso por uma inclinação em seu eixo "(Robertson, 2016). Embora as margens de votação não tenham sido esmagadoras, com os votos para "deixar" [a União Europeia - UE] em 51,9 por cento e para "permanecer" em 48,1 por cento, os ativistas a favor da saída da UE insistiram que "o povo" havia manifestado sua vontade.

Nos dias que se seguiram, um padrão ficou claro. Enquanto o voto do "povo" para sair da UE amalgamou-se em torno das questões de migração (intra-européia e refugiados) e de soberania nacional, um exame minucioso dos eleitores e seus padrões de votação revelou uma questão estrutural subjacente. Aqueles que votaram a favor do Brexit' pertenciam, em grande medida, a grupos socioeconômicos que foram deixados para trás como resultado de políticas neoliberais que haviam gerado a desindustrialização, a crise financeira global de 2008 e uma década de austeridade (Dorling e Tomlinson, 2019). Ao invés de se ver todos os barcos subindo (melhoria no padrão de vida para todos), que havia sido o mantra dos evangelistas neoliberais ${ }^{2}$, os que votaram para sair tornaram-se significativamente mais pobres, estavam em situação pior do que uma década antes (Dorling e Tomlinson, 2019). Eles também eram menos instruídos, ou cuja educação não se traduzia na promessa de um emprego bem remunerado. Pode-se argumentar, portanto, que o voto a favor do Brexit era sintomático 
de transformações mais profundas que ocorreram nos últimos quarenta anos. Os defensores do Brexit relativamente abastados da elite política eurocéptica haviam conseguido tocar no ponto nevrálgico do ressentimento daqueles que foram deixados para trás, transformando o voto a favor da saída da UE em um desabafo contra um inimigo imaginário, refugiados, migrantes e Europa (Eco, 2013).

O Brexit, como os ativistas organizadores da "saída" passaram a chamá-la, estava destinado a levar o Reino Unido e a UE a águas desconhecidas. Nenhum país-membro da UE havia tentado se desentranhar dos múltiplos emaranhados e interdependências decorrentes de anos de aproximação e integração. Para o Reino Unido, grande parte das atividades de Estado em conjunto - de segurança e defesa ao movimento de pessoas, bens e serviços - teriam que ser desassociadas e novos tipos de conhecimento precisariam ser encontrados rapidamente ${ }^{3}$.

Se o Brexit era um assunto muito britânico, também fazia parte de uma questão global. Pois, como Nancy Fraser observou em um artigo publicado em 2017, "... não faltam casos análogos em outros lugares" (p. 1). Desde a eleição de Trump nos Estados Unidos em novembro de 2016, a desintegração dos partidos de direita do centro socialdemocrata na Europa e a eleição de candidatos de extrema-direita e populistas na América Latina, demonstrando que uma nova ordem mundial e sua 'desordem', estava se tornando aparente. Se foi uma crise política global, quais foram suas causas?

Por ser próximo de casa e o foco deste capítulo, essas questões são importantes e precisam ser entendidas de perto e com sabedoria, analisando historicamente um longo período de tempo. Como chegamos aqui? E o que isso pode significar para o futuro da educação superior europeia, seus vários instrumentos e processos e, também, para o Reino Unido? A educação superior está implicada nesses desenvolvimentos, uma vez que uma linha de clivagem é chamada de segmentação educacional (Bovens e Wille, 2017)? Com isso, Bovens e Wille querem dizer que a natureza das qualificações educacionais mapeia posições pró e anti-Europa; pró e anti-Brexit, pró e anti-Trump ${ }^{4}$.

E essa não era a única linha de fratura. As crescentes divisões entre as comunidades no Reino Unido, particularmente em torno do Islã, foram alimentadas por um departamento do governo hostil, cujos projetos de controle de imigração e vigilância estavam causando efeitos profundos no setor de educação superior do Reino Unido. $O$ que essas clivagens nos dizem sobre as novas formas de imperialismo e as políticas culturais do neoliberalismo e seus efeitos materiais? Como esse complexo e ágil conjunto de dinâmicas moldou e foi moldado pelas políticas, programas e práticas de educação superior?

No restante deste artigo argumentarei que, para entender essa dinâmica, precisamos identificar uma série de rupturas e crises que tiveram profundas conseqüências sociais, políticas e econômicas na sociedade mais ampla, bem como, especificamente, no setor de educação superior. Na seção seguinte, eu as enquadrarei como uma série de distintas e discretas, embora relacionadas internamente, mudanças de poder (powershifts). 
ROBERTSON, S. L.

\section{MUDANÇAS DE PODER (POWERSHIFTS)}

Powershifté o título de um muito influente livro de Alvin Toffler5, publicado após o colapso do bloco soviético em 1989, que demarca o fim da Guerra Fria, iniciada a partir da década de 1950. Pergunta Toffler, neste livro, como poderia ser o futuro sem mais ameaças inerentes à Guerra Fria. Ele observa que "o fim da Guerra Fria não apenas trouxe mudanças de status, mas uma nova redistribuição [de poder] entre estados, mercados e sociedade civil. A constante concentração de poder nas mãos dos estados, que começou em 1648 com a paz da Vestfália acabou, pelo menos por um tempo "(Toffler, 1991: 1).

Em suma, o colapso do império soviético abriu as portas para a nova redistribuição, ou mudança, do poder para cima, para fora e para baixo. Isso incluiu a posterior expansão dos mercados capitalistas para os países pós-socialistas, bem como para as esferas de política social previamente desmercantilizadas, uma ampliação do domínio dos EUA na economia e na sociedade globais, um revigoramento de regionalismos em todo o mundo (Robertson et al., 2016) e a intensificação da governança e da influência das instituições multilaterais (Sassen, 2006). Neste capítulo, abordarei o uso de Toffler da ideia de 'powershift' ${ }^{6}$ para sinalizar rupturas significativas nos arranjos institucionais e sociais existentes, possibilitando a recalibração da redistribuição de poder e a regulação do controle entre forças sociais concorrentes que operam em múltiplas escalas.

Nesta seção, apresento quatro 'powershifts', que são essenciais para a compreensão do ensino superior contemporâneo no Reino Unido, particularmente, e com consequências para a Europa. O Powershift 1 examina a crise econômica global da década de 1970, o surgimento do neoliberalismo como projeto político e sua expansão para o exterior. $O$ Powershift 2 explora os eventos que cercam o momento agora icônico - "11 de setembro de 2001", dando origem a novas formas de imperialismo, conflito, intensificação da vigilância e da securança e movimento global das populações de refugiados. O Powershift 3 aborda as conseqüências inevitáveis da ascensão do capital financeiro e da fraca supervisão do Estado, levando à crise financeira global em 2008, ao resgate dos bancos e aos efeitos subsequentes na redistribuição. O Powershift 4 leva-nos à conjuntura atual - a partir de 2016 - marcada por um aumento do poder autoritário, políticas populistas, crescente racismo e xenofobia e uma situação cada vez pior para as classes baixa e média.

Argumentarei que cada powershift emerge de uma crise nas esferas da economia, da política e do mundo cultural ou da vida. Intervenções são esforços para conter e estabilizar essas tendências de crise por meio de projetos de governança espacialmente estratégicos. Em suma, como veremos, embora nem Trump nem Brexit tenham sido planejados, eles poderiam muito bem ter sido previstos como resultados prováveis de projetos políticos e suas conseqüências materiais para a vida cotidiana e o mundo da vida (Sayer, 2011).

Essas mudanças podem ser amplamente rastreadas através de três lógicas de poder. As duas primeiras lógicas são o que Arrighi (1994: 33-34) chama de lógicas "territorial" e "capitalista". Eu argumentaria que há também uma terceira lógica - a criação do 'indivíduo social' - cujo mundo da vida e visão de mundo emerge da interação social, da criação de sentido e identidade (Bernstein, 2000; Fourcade, 2016). 
Cada um é diferente do outro, pois as motivações e desejos, situações e processos desses agentes diferem em relação a essas lógicas e no que deve ser focado. Por exemplo, embora o capitalista detentor de dinheiro deseje colocá-lo onde quer que seja possível obter lucros, a fim de acumular mais capital, localizados territorialmente, políticos e estadistas buscarão resultados que sustentem ou aumentem o poder de seu próprio estado em relação a outros estados, e em relação aos seus cidadãos.

O indivíduo social, no entanto, emerge de encontros reflexivos, mediados pela semiótica, com outros/idéias/objetos, cujas categorias estruturantes produzem "eus" [indivíduos] sociais, modos de ver e ser e ordens sociais. Essas três lógicas podem muito bem se opor à outra, pois o lucro, a criação de estados e a identidade nem sempre são mapeados entre si. Ao mesmo tempo, essas lógicas também podem se reforçar; por exemplo, quando o estado territorial garante estruturas políticas que permitem o acúmulo de propriedades, em que tipos específicos de identidades legitimam a capacidade do estado de governar ou quando visões de mundo específicas reforçam a priorização de lógicas específicas em novas esferas da vida social.

\section{POWERSHIFT 1 - MERCADOS INSURGENTES / MENTES INDIVIDUALIZADAS}

Muito foi escrito tanto sobre esse primeiro powershift, tanto de maneira mais geral quanto em relação especificamente à educação superior. No centro deste debate está o estabelecimento e a incorporação do neoliberalismo como ideologia organizadora, a criação de sociedades de mercado (Slater e Tonkiss, 2001; Leys, 2003) e a civilização de mercado (Seabrooke e Bowden, 2004). Como e por que isso aconteceu e quais foram as implicações para o educação superior na Europa na época e em relação aos desenvolvimentos atuais?

O ponto de referência para esse primeiro powershift foi o emblemático 'choque de petróleo' na década de 1970 (Harvey 1989). Na verdade, no entanto, no final dos anos 60 , era evidente que o crescimento econômico no mundo industrializado havia começado a desacelerar, com mercados internos saturados e margens de lucro caindo (Streeck, 2014a). As empresas foram à procura de novos mercados de exportação para sua produção excedente, para locais com custos trabalhistas mais baixos, com menos regulamentações governamentais (Harvey, 1989: 141-2). De maneira mais geral, o período de 1965 a 1973 foi caracterizado como aquele em que o modelo de desenvolvimento do fordismo e keynesianismo pós-Segunda Guerra não foi capaz de conter as contradições internas do capital. O motor econômico - capital - que alimentava o capitalismo estava com problemas (Harvey, 2014: 10-11). A hegemonia do Estado Keynesiano de Bem-Estar Nacional e do modelo de produção fordista entrou em crise (Jessop, 1999).

A recessão global da década de 1970 que se seguiu abriu um novo terreno para as lutas - entre keynesianos e neoliberais hayekianos (Hobsbawm, 1994: 409), mas também as lutas de grupos subalternizados (gênero/etnia/raça) opostos à opressão por estruturas burocráticas, patriarcais e raciais. Embora a vitória Hayekiana não tenha sido imediata, como Peck (2013) revela em seu livro Constructions of Neoliberal Reason, as contínuas crises do keynesianismo (um modelo de tamanho único que se ajusta a todos 
ROBERTSON, S. L.

os governos burocráticos/estatais), bem como reivindicações poderosas sobre a exploração dos bens públicos e comuns (tese da sobrecarga de governo - overloaded government thesis), jogaram com e para os que reivindicam a liberdade de mercado e as políticas de reconhecimento e diferença.

No entanto, a base para um novo modelo de desenvolvimento econômico e social não era imediatamente óbvia, embora houvesse vários candidatos, incluindo a ideia de uma economia de aprendizagem (Lundvall e Johnson, 1994), de uma sociedade em rede (Castells, 1996) e de uma sociedade do conhecimento (UNESCO, 2005). Porém, em meados da década de 90, a idéia de uma economia "baseada no conhecimento" foi cada vez mais adotada pela OCDE (Foray, 2004), tendo a própria OCDE e o Banco Mundial investido, ambos, em conjuntos de indicadores para "medir" as economias baseadas no conhecimento (Robertson, 2009).

Se as economias do conhecimento dependiam do aumento dos estoques de conhecimento (como capital humano), suas decisões também foram moldadas pela visão de que o Ocidente tinha uma vantagem comparativa em setores como a educação, que poderiam formar a base de novos acordos comerciais. As metas de cobertura para a educação superior foram estabelecidas de modo a aumentar as taxas de matrículas nacionais e para abrir os setores de educação a estudantes estrangeiros que pagam anuidades integrais. No caso do Reino Unido, isso significava apoiar-se em velhos laços coloniais, como Hong Kong, Malásia, Índia, Paquistão e Nigéria, para recrutar estudantes que pagam integralmente as taxas em universidades do Reino Unido (Robertson e Kedzierski, 2016). Os países que abriram seus setores de educação superior a estudantes estrangeiros onerados com taxas integrais também tinham departamentos governamentais que prospectavam mercados e grupos privados interessados (empresas que procuram entrar em setores de serviços públicos que eram em grande parte monopólios governamentais) que estavam ocupados negociando em nível multilateral para incluir a educação como serviço em acordos comerciais, como o Acordo Geral sobre Comércio de Serviços da Organização Mundial do Comércio (Robertson et al., 2002).

Nesse novo contexto de concorrência global e de tratamento da educação como serviço, as universidades ficariam encarregadas de impulsionar o desenvolvimento de uma economia do conhecimento competitiva por intermédio da criação de produtos ricos em conhecimento (como resultado de idéias que levaram a inovações), de uma nova geração empreendedores e, ao estimular uma cultura de start-ups, estimulariam o surgimentos de empresas e o registro de propriedade intelectual. As universidades seriam também locais para novas formas de financeirização - por meio de concessão de empréstimos e outras formas de crédito a estudantes, instituições e nações.

Os amplos detalhes dessa narrativa agora são uma história familiar, mas como classificar este powershift? Em essência, era algo que vinha a promover uma mudança no próprio tecido da sociedade e em suas relações sociais constituintes (Leys, 2003), como a sociedade de mercado (Slater e Tonkiss, 2001). O neoliberalismo, como projeto político, desencadearia a desestruturação do antigo contrato social, estendendo as regras do capitalismo em domínios de política social anteriormente desmercadorizados, como a educação, implicando na remodelação tanto da vida institucional como dos indivíduos. Essa era a cultura do novo capitalismo (Sennett, 2006), com a própria educação sendo encarregada de produzir e reproduzir essa nova cultura. 
A educação superior, de maneira sumária, pode ser considerada globalizada e regionalizada. Projetos de regionalização surgiram como proteção contra a turbulência da globalização neoliberal (Hettne e Söderbaum, 2000). O mais notável para a educação superior na Europa foi o Processo de Bolonha (1999). Isso exigiu a criação de uma estrutura única que redefinisse o sistema de graus na Europa e além deste continente. Um setor europeu competitivo de educação superior pretendia limitar o movimento de estudantes de pós-graduação para os Estados Unidos (Robertson e Keeling, 2008). Ao fazê-lo, também ajudaria a impulsionar a Agenda de Lisboa aprovada pela Comissão Europeia (Robertson et al., 2016). Esta Agenda de Lisboa era uma estratégia que visava criar uma economia dinâmica e competitiva e uma Europa socialmente coesa por intermédio de um programa de crescimento coordenado nacionalmente de investimentos em pesquisa, educação superior e novas tecnologias (Robertson et al., 2016). A reunião de Lisboa forneceu um mandato e uma agenda para estender o alcance da responsabilidade política da Europa mais profundamente no território nacional educação - e, eventualmente, para o resto do mundo. A Agenda de Lisboa também confirmou uma compreensão neoliberal da contribuição da educação superior para o bem-estar socioeconômico da região e para a construção e garantia de capital humano.

Indiscutivelmente, o país europeu de maior sucesso na transformação de aspectos-chave da vida social em uma sociedade de mercado foi a Inglaterra ${ }^{7}$. A criação de um mercado de educação superior ganhou impulso considerável após o desmantelamento do financiamento para os cursos de graduação "RU/UE" nas universidades e o estabelecimento de um sistema de empréstimos para estudantes legitimado por narrativas como poupança pública, promoção da justiça para aqueles que não acessam universidades e estipulação de um "prêmio" para quem termina a pósgraduação 8 .

De acordo com argumentos a favor das autoridades governamentais, a questão política urgente seria como "... ampliar o acesso, sustentar e melhorar os padrões de excelência universitária em um contexto global cada vez mais pressionado e em um ambiente de gastos públicos mais restritos" (BIS, 2009: 3). Em outras palavras, qual a melhor maneira de abrir mais vagas na educação superior sem aumentar o ônus financeiro de longo prazo para o erário público.

Foi essa questão que estabeleceu os termos de referência para o relatório Independent Review of Higher Education Funding and Student Finance ("Relatório Browne" , coordenado por John Browne, ex-diretor executivo da multinacional de petróleo e gás BP - antes denominada British Petroleum Company) de 2010. Baseado neste argumento, contemplado no Relatório Browne, o Higher Education Funding Council for England (HEFCE) financiava parcialmente com base no critério de número de matrículas em educação superior. No entanto, o HEFCE limitou seu desembolso anual ao impor um limite no número máximo de estudantes em cada instituição. O Relatório Browne (Browne, 2010) incorporou em suas recomendações a retirada do subsídio em bloco para ciências sociais, humanidades e artes (mas, protegendo áreas de ciências, tecnologia e áreas vulneráveis, como ensino de idiomas). Também recomendou a elevação significativa do teto das anuidades por estudante para permitir que as universidades recuperassem o financiamento. 
ROBERTSON, S. L.

Os aumentos de taxas de anuidades foram justificados com a observação de que, contrariamente ao que muitos imaginaram, mesmo com aumento do teto das contribuições dos estudantes, em 2006, para $£ 3.000$ libras, não houve o desencorajamento dos alunos na procura por educação superior. Em vez disso, a demanda por vagas universitárias havia aumentado (Brown, 2011:20). O Relatório Browne também propôs uma mudança no sistema de empréstimos para estudantes, impondo encargos dos custos de seus diplomas de graduação. Os reembolsos dos débitos começariam na proporção de $9 \%$ da renda, sobre salários acima de $£ 21.000$, durante um período de 30 anos após a colação de grau (graduação). O dinheiro não devolvido durante esse período seria amortizado pelo Estado.

No entanto, o efeito de estabelecer um limite superior ( $£ 9.000$ libras na época) significou que a maioria das universidades inglesas, independentemente de sua missão, status ou origem social de seus estudantes, passou a cobrar dos alunos o valor máximo ou próximo do teto e não o valor recomendado de $£ 6.000$ libras. Isso não apenas criou novos problemas para o Estado em termos de encargos financeiros dos empréstimos para estudantes até que os alunos pagassem o empréstimo, mas a determinação de instituir um mercado competitivo e orientado para o consumidor na Inglaterra apresentou ao governo outras dores de cabeça. Como McGettigan (2012) mostra, essas "economias" nada mais eram do que um truque contábil. Ao transferir o financiamento da educação superior de um subsídio institucional (transferência de fundos para as IES) para um empréstimo de recursos aos estudantes garantido pelo governo, o mesmo estava usando técnicas de "off-balance accounting" ("débitos fora do balanço contábil"), o que significa que os valores referentes a financiamentos a estudantes, contabilmente, não seriam exibidos em rubricas que aumentariam o déficit governamental.

Mais importante, esses novos arranjos de financiamento abriram as portas para provedores privados de educação superior, com fins lucrativos - por exemplo, a Pearson Education, listada no FTSE $^{9}$-, para entrar no setor, com seus alunos habilitados a acessar empréstimos estudantis concedidos pelo $\mathrm{Estado}^{10}$. Antes disso, esses provedores estavam excluídos. Em razão da mercantilização e da financeirização, a educação superior inglesa estava se aproximando para ser mais plenamente mercadorizada.

Streeck (2014a) mostra que essa primeira crise e sua subsequente mudança sociopolítica e espacial no poder (powershift), do estado para o mercado, implicaram no aumento dos níveis de dívida pública e familiar. Os esforços para expandir e atender setores como a educação, para satisfaer às demandas de uma economia baseada no conhecimento são, ao mesmo tempo, prejudicados por acordos governamentais com empresas para reduzir a tributação sobre elas (diante da ameaça de que tais empresas iriam para outro lugar). A privatização da dívida da educação para as famílias foi possibilitada por oportunidades mais generosas de acesso ao crédito e níveis sem precedentes de endividamento (Streeck, 2017: 7).

Essas desigualdades distributivas serão importantes de várias maneiras, como veremos no terceiro e quarto powershifts. A questão é por que e como? Para começar, a unidade contraditória entre produção e realização se torna muito mais difícil de manter em equilíbrio quando os hábitos confiáveis e não discricionários dos trabalhadores pobres são eclipsados pelos caprichos dos ricos. Para o capitalismo funcionar, é preciso haver um circuito do capital; aqueles que consomem precisam de recursos financeiros para garantir que o que é produzido possa ser pago (Harvey, 2014: 168). Níveis cada vez 
maiores de endividamento precisam, com muito custo, ser atendidos. Isto impõe limites no poder de compra dos graduados - incluindo a formação de novas famílias, a compra de casas etc. Segundo, a promessa de um retorno da educação como investimento - o prêmio de pós-graduação - não foi cumprida por muitos grupos, levando a uma paralisação, se não à reversão, da mobilidade social. Tais desdobramentos abrem caminho para uma perda de confiança no sistema que parece deixá-los em pior situação e para o surgimento de ressentimento com as elites, que configura extrair, desproporcionalmente, uma parcela maior de benefícios de uma espécie de distribuição regressiva.

\section{POWERSHIFT 2 - MENTES INSURGENTES / ESTADOS DE VIGILÂNCIA}

Deve-se notar que havia outras dinâmicas em ação na reformulação dos setores do educação superior na Europa e, particularmente, no Reino Unido. A potência de seus efeitos no ensino superior deveu-se, em parte, à maior integração do ensino superior nos circuitos globais do capital. Assim, qualquer distúrbio político também poderia encaminhar tremores ao mundo do ensino superior por meio de sua expansão como mercado global, repercutindo acusações de que as instituições de ensino superior possam ser precursoras de mentes insurgentes. Isso fica mais visível nos dias, semanas e meses que se seguiram ao ataque da Al Qaeda às Torres Gêmeas nos EUA em 11 de setembro de 2001, à subsequente invasão do Iraque em 2003 e às guerras civis ao longo da década na Líbia, Síria e lêmen.

É tentador ver esses eventos através do prisma da Al Qaeda, '11 de setembro' e da invasão do Iraque. No entanto, isso estava longe de ser o caso. Ali (2003) ressalta que em 1997 foi publicado o Project for the New American Century [Projeto para o Novo Século Americano]. Nesta publicação, argumenta-se que os Estados Unidos da América não poderiam ser complacentes com o fim da Guerra Fria. Entre os principais signatários do projeto estão Dick Cheney, Jeb Bush e Donald Rumsfeld (Ali, 2003: 7-8); membroschave do governo Bush, que coordenaram guerras no Afeganistão e no Iraque. Em 2001, forças ocidentais invadiram o Afeganistão - sancionadas pela ONU e apoiadas pela OTAN. Foi o primeiro ponto na escalada na chamada "guerra global ao terror" (Ali, 2008: 19). Dois anos depois, o "trauma nacional do 11 de setembro" foi usado para cumprir uma agenda imperial audaciosa, na qual a ocupação do Iraque era uma das ações em uma série que lançava uma nova agenda imperialista dos EUA (Ali, 2003: 7).

O relato de Harvey (2003) sobre o ataque ao Iraque também é esclarecedor - e deve ser interpretado pelas lógicas predatórias do capital, por um lado, e da administração do estado norte-americano de suas próprias crises internas, por outro:

A recessão que começou no início de 2001 ... não desapareceu. 0 desemprego estava aumentando e a sensação de insegurança econômica era palpável, os escândalos corporativos caíam em cascata e impérios corporativos, aparentemente sólidos, estavam literalmente se dissolvendo da noite para o dia ... O saldo da conta corrente com o resto do mundo [balanço de pagamentos] passou de mal a pior quando os Estados Unidos se tornaram a maior nação de- 
ROBERTSON, S. L.

vedora de todos os tempos. Há muito que a desigualdade social está aumentando, mas o fetiche de corte de tributos do governo parece aumentar ainda mais (Harvey, 2003: 12).

Semelhante a Ali $(2003,2008)$, Harvey argumenta que diante de uma combinação da ausência da ameaça da Guerra Fria e, portanto, de nenhum claro inimigo, e no contexto de crescente precariedade e de medo, o governo dos EUA precisava de um novo inimigo. Adicione-se a isso o interesse geopolítico e econômico dos EUA no petróleo e uma presença controladora no Oriente Médio. Assim, o cenário foi montado para uma nova etapa do imperialismo dos EUA (Harvey, 2003: 22).

O desencadeamento de forças de oposição e a desintegração da civilidade desencadearam o desenrolar de relacionamentos frágeis e alinhamentos complicados em todo o Oriente Médio, que ricochetariam de volta ao Ocidente com fúria. A guerra contra o terror tornou-se uma guerra de terrores. É importante ressaltar que o deslocamento de um grande número de civis como resultado de guerras na Ásia Central e no Oriente Médio, juntamente com conflitos na África do Norte e Subsaariana, alimentaria um dos maiores movimentos de pessoas em direção à Europa desde o final de a segunda Guerra Mundial. Segundo o Alto Comissariado das Nações Unidas para Refugiados (ACNUR UNHCR em inglês: United Nations High Commissioner for Refugees), havia cerca de 68,5 milhões de pessoas deslocadas à força no mundo, incluindo 25,4 milhões de refugiados (UNHCR/ACNUR, 2017). Estudantes e acadêmicos foram apanhados nessa massa de deslocamento, concentrados em campos ou em busca de uma nova vida na Europa.

Este powershiftmotivado de forma imperialista teve consequências previsíveis e trágicas em vários locais ao redor do mundo. Ataques em Londres, Madri, Indonésia ... e depois em Paris, Bruxelas, Manchester, Istambul e Londres desencadearam novas rodadas de vigilância. Sendo que muitos desses agentes de violência com bombas e simpatizantes foram educados em casa e, em alguns casos, bem educados. De modo que as universidades passam a ser identificadas como potenciais locais de radicalização. Os efeitos foram imediatos, tanto em termos da relação entre determinados cidadãos e seu estado de origem, quanto a graduação em educação superior. Em razão do contingente fluxo transfronteiço de estudantes, qualquer repressão deliberada a centros "terroristas" e países islâmicos ou medidas de identificação e contenção contribuíram para a experiência de estar sob vigilância. Uma nova política de segurança e vigilância surgiu no coração da Europa, com grandes consequências para a vida social cotidiana. Os vistos demoraram ou foram rejeitados. As filas nos aeroportos aumentaram, assim como os esforços para detectar o próximo insurgente. Os EUA e o Reino Unido deixaram de receber estudantes que se voltaram para novos destinos vistos como menos hostis, a exemplo de Canadá, Austrália, Alemanha.

Em 2003, CONTEST [United Kingdom's counter-terrorism strategy] foi lançada como uma estratégia de segurança destinada a combater o terrorismo, com muçulmanos e bairros muçulmanos considerados particularmente "em risco" (Heath-Kelly, 2013). "Prevent" é uma das quatro vertentes dessa abordagem geral, embora com o tempo seu foco tenha mudado, com as instituições de ensino superior sendo focadas para sua implementação. Deveres estatutários de "Prevent duty" incluem o monitoramento, de maneira a impedir que "pessoas sejam atraídas para o terrorismo" (HEFCE, 2017:4). Como observam Glees e Pope (2005), o Ministério do Interior [Home Office] foi convencido pela descoberta de que alguns dos terroristas responsáveis pelos atentados de Londres em 
julho de 2005 haviam estudado nas universidades britânicas. Como resultado, as universidades eram vistas como lugares onde visões extremistas poderiam ser promovidas e, portanto, um campo de recrutamento para potenciais "jihadistas". Os professores receberam novos papéis, entre os quais de relatar comportamentos suspeitos que se presuma serem evidências de radicalização e de declarar todos os convites a palestrantes externos para garantir que os radicais religiosos não recebam uma plataforma.

"Prevent" foi lançada não apenas no Reino Unido, mas em toda a Europa. As estratégias de "prevenção" em relação à educação superior têm sido particularmente controversas, especialmente entre estudantes e professores. Os requisitos de relatórios de "Prevent" para as instituições de educação superior no Reino Unido despertaram sentimentos de alienação entre estudantes muçulmanos. Há também uma inferência de que qualquer crítica ao Reino Unido e aos valores britânicos seja vista como uma tendência a uma posição extremista. Por sua vez, isso coloca novos tipos de limites à liberdade acadêmica (Saeed e Johnson, 2016).

A construção pelo Estado, pela mídia e por populações temerosas de que comunidades muçulmanas sejam abrigadoras, se não provedoras do inimigo interno (Eco, 2013), havia desencadeado uma xenofobia divisória que reforçava novas divisões de 'nós' contra 'eles'. Na academia, os efeitos foram perniciosos. Como Saeed e Johnson (2016: 39) observam, a Lei de Contra Terrorismo e Segurança, de 2015, torna obrigatória que as universidades denunciem estudantes potencialmente suspeitos, mas "a ideia de ser monitorado, a sensação de ser considerado culpado por motivos de associação religiosa, é um sentimento familiar para os estudantes muçulmanos ". No estudo de Saeed e Johnson (2016), os alunos relatam sentirem-se destacados, observados e com medo do que poderia acontecer. Esse senso de ameaça não era apenas uma reserva dos estudantes. Os acadêmicos também se sentiam vulneráveis. No campo acadêmico, de maneira mais ampla, também colocaram-se limites à liberdade de expressão. $O$ extremismo foi definido como oposição aos valores britânicos fundamentais, incluindo a democracia, o estado de direito, a liberdade individual e o respeito mútuo.

Com esse segundo powershift, novos conjuntos de conluios e colisões foram acionados na casa de forças (powerhouse) do conhecimento, daqueles [conluios e colisões] que criaram um novo conjunto de divisões no cenário da educação superior. Administradores e acadêmicos eram vistos como se estivessem em conluio com o estado. Também houve uma colisão de lógicas - entre a expansão de um setor global de serviços de educação superior, tendo o Reino Unido como um destino desejável, e a preocupação do Reino Unido, agindo como um Estado organizado, com a vigilância e o terrorismo no interior da academia. Juntos, eles exibem os múltiplos registros de violência que levaram a mudanças sísmicas nas relações sociais dentro da academia.

\section{POWERSHIFT 3: CAPITAL FINANCEIRO RESSURGENTE / ESTADO AQUIESCENTE}

Em 15 de setembro de 2008, o que vinha se formando como uma verdadeira tempestade sobre hipotecas subprime no setor imobiliário nos EUA em 2007, explodiu em uma crise bancária global, quando o banco de investimento, o Lehman Brothers, en- 
trou em falência. $O$ excessivo risco assumido pelos bancos em torno dos empréstimos, a busca maior de lucros pelas corporações bancárias com produtos inovadores e a fraca regulamentação governamental do setor em centros financeiros como Londres e Nova York foram os ingredientes de uma perfeita tempestade. Como um castelo de cartas, a acumulação e a alta taxa de inadimplência dessas hipotecas subprime levaram a uma rápida desvalorização dos instrumentos financeiros (títulos lastreados em hipotecas, carteiras de empréstimos em pacote, derivativos e swaps de títulos em inadimplência). À medida que o valor desses ativos despencava, o mercado desses títulos evaporou e os bancos fortemente investidos começaram a experimentar uma crise de liquidez.

Havia uma grande quantidade de bancos a seguir, com poupadores lutando para retirar o que podiam. As negociações de alto nível eram permeadas pela temeridade sobre o futuro, já que o Federal Reserve Bank, o Banco da Inglaterra, o Banco Europeu de Investimento e o Fundo Monetário Internacional tentaram preencher a crise de liquidez com uma injeção de bilhões. Os efeitos indiretos para o mercado de ações global foram profundos. Essa foi a crise financeira mais séria desde a Grande Depressão da década de 1930. A escala do fracasso promoveu Alan Greenspan, ex-chefe do Federal Reserve dos EUA, a apontar para o que deveria ser agora uma crise existencial para a profissão de economista, dada sua propensão a modelos de previsão econômica (Green e Hay, 2015). Como é que ninguém viu isso acontecer, foi um refrão comum.

Como Streeck (2014a) nos lembra em seu relato do período, um dos problemas daqueles que analisam a acumulação de capital e suas tendências de crise é que eles deixaram de pensar no capital como capaz de ter um objetivo estratégico. Em vez disso, tratamos o capital como um meio de produção e não como uma classe cujos interesses e motivações são buscar a atividade econômica e gerar lucros. Nesse sentido, o capital havia se tornado uma fonte de destruição criativa e não um ator nos anos que se seguiram à crise da década de 1970. Streeck (2014a: 19) argumenta: "quando o capital provou ser um jogador em vez de algo que esteja em disputa, um predador em vez de um animal de trabalho, com uma necessidade urgente de se libertar da estrutura institucional do tipo gaiola da economia social de mercado do pós-guerra de 1945 ", tendemos a nos surpreender.

No entanto, a evidência estava lá para todos verem. Esta foi uma guerra de classes, sendo empreendida pelo capital financeiro para reverter o projeto de distribuição social da renda do pós-guerra. Isso pode ser visto na entrevista com a quarta pessoa mais rica do mundo, Warren Buffett, no New York Times, em 2006: “... com certeza há uma guerra de classes, e é a minha classe, os ricos, quem está fazendo isso e nós estamos ganhando"(Stein, 2006: 1). Mas essa não é apenas uma história sobre a ascensão do capital financeiro e seu comportamento predatório e não controlado. Pelo contrário, foi o resultado inevitável da reestruturação neoliberal descrita no primeiro powershift, elaborado anteriormente. Embora os defensores da reestruturação neoliberal tenham prometido um grande aumento no investimento a partir do momento em que os negócios do capital fossem liberados da regulamentação estatal, do sistema tributário progressivo e das pressões sindicais (Kotz, 2018: 39). Mesmo que tenha havido um boom nos anos 90 em torno das tecnologias da informação e com uma grande expansão nos anos 90 e década de 2000, que foi impulsionada pelos gastos dos consumidores financiados por dívida. Kotz (2018: 4) argumenta que esses processos criaram três desenvolvimentos insustentáveis que acabariam por levar à crise estrutural do capitalis- 
mo neoliberal: (i) aumento da dívida do setor privado; (ii) novos títulos derivativos de bancos rentistas (rent seeking banks), que obtiveram enormes lucros lançando este tipo de papel [derivativos] no mercado financeiro; e (iii) uma taxa decrescente de lucro e excesso de capacidade industrial. Tomados em conjunto, esses desdobramentos criaram uma nova crise fiscal do estado contemporâneo, refletida na escalada da dívida pública desde a década de 1970. Streeck argumenta que, substituindo as receitas fiscais por empréstimos,

... os governos contribuíram ainda mais para a desigualdade, na medida em que ofereceram oportunidades seguras de investimento àqueles cujo dinheiro eles não poderiam mais confiscar e tiveram que pedir emprestado. Diferentemente dos contribuintes, os compradores de títulos do governo continuam a possuir o que repassam ao Estado e, de fato, recebem juros sobre o montante, normalmente pagos com impostos cada vez menos progressivos, tornando-se herança (o que foi emprestado ao Estado) a ser transferida para seus filhos. Além disso, o aumento da dívida pública pode ser e está sendo utilizado politicamente para argumentar por cortes nos gastos do Estado e pela privatização de serviços públicos, restringindo ainda mais a intervenção democrática redistributiva na economia capitalista (Streeck, 2014a: 43).

O economista Thomas Piketty, que analisa o funcionamento e os resultados do capital financeiro ressurgente em seu livro Capital in the $21^{\text {st }}$ Century (2014), observa que, se deixada por conta própria (fracos arranjos institucionais para redistribuição por meio de tributação progressiva e pressão por altos rendimentos para o topo da pirâmide social), a distribuição da riqueza tenderá à maior concentração, produzindo por sua vez ainda mais desigualdades. Em outras palavras, a desigualdade é produzida tanto pela desigualdade do trabalho (diferenças salariais) quanto pela desigualdade do capital (riqueza anteriormente possuída).

Como serviço público, a educação foi vítima do endividamento do estado, assim como os salários dos servidores públicos, os investimentos em infra-estruturas e a redistribuição de renda para diminuir as desigualdades, tudo que pertence à esfera pública está sob pressão. Paralelamente ao aumento da dívida pública, houve o aumento da dívida privada. Isto também influencia no nível de desigualdade na educação à medida que mais e mais famílias são chamadas a arcar com os custos da competitiva corrida pela educação. A pronta disponibilidade de crédito, juntamente com a pressão descendente sobre os salários, levou ao que Colin Crouch chama de "keynesianismo privatizado", ou seja, a substituição da dívida pública pela dívida privada como mecanismo de expansão do estoque de recursos na economia nacional (Crouch, 2011: 97-124). Em nenhum lugar isso é mais evidente do que nos setores de educação superior do Reino Unido e dos EUA. Os números para os EUA (2015) mostram que mais de US $\$ 1,2$ trilhão reprepresentam a dívida de empréstimos a estudantes, envolvendo 40 milhões de mutuários, com um saldo médio de US $\$ 29.000$ em débitos (Holland, 2015: 1). Em 2017, no Reino Unido, foi relatado que a dívida em empréstimos estudantis aumentou $16,6 \%$, para $£ 100,5$ bilhões de libras no final de março de 2017 , ante $£ 86,2$ bilhões de libras um ano antes, com a Inglaterra 
representando $£ 89,3$ bilhões de libras do total (Monahan e Wiele, 2017). Não são apenas os aumentos nas taxas pagas às IES que pressionaram os orçamentos das famílias e criaram níveis sem precedentes de dívida. Os alunos são pressionados a incrementar cada vez mais seus currículos, sendo necessário gastos suplementares. Isso criou um espaço para financeiras privadas oferecerem novos tipos de empréstimos para permitir mobilidade, atividades de extensão e tutoria.

Prosseguir com a educação em um mundo altamente competitivo é um negócio caro, pois significa volumes cada vez maiores de recursos sendo reunidos e investidos em capitais cultural, social e político, que farão a diferença na sua posição na hierarquia de status e na competição por talentos. Mas em um mundo que passou a vincular 'talento' a salários muito altos e justificar salários muito altos como recompensa por talentos, para vencer essa corrida, vale a pena o investimento (Brown, Lauder e Ashton, 2011; Newfield, 2010). Como em qualquer corrida, no entanto, existem vencedores e perdedores, embora o tamanho do grupo de perdedores esteja aumentando à medida que o "vencedor leva tudo". Como em todas as corridas, no entanto, as regras para o engajamento na competição, como se pode imaginar, são sempre estrategicamente seletivas - de alguns em relação a outros. Este é o poder que importa, com a agressividade de um chute na canela! Como Brown, Lauder e Ashton observam: “... se o sistema capitalista não tem lealdade aos trabalhadores norte-americanos, o mesmo pode ser dito das elites corporativas norte-americanas. Elas simplesmente não jogaram um jogo de vencedor, ao estilo "quem ganha leva leva tudo"; eles criaram um" (2011: 115).

Os problemas são agravados ao considerar as mudanças que ocorreram na reorganização do mundo do trabalho globalmente e o que isso significa para os retornos econômicos. Brown, Lauder e Ashton (2011) mostram em seu livro The Global Auction, como mercados de trabalho, produção e salários nacionais foram transformados por processos globais. Uma chave dinâmica no trabalho aqui é a maneira pela qual locais de custo de trabalho relativamente baixo em relação ao mundo - Índia, China, Indonésia, Vietnã e assim por diante - podem reduzir o preço de mercado do know-how tecnológico. Eles apontam para a disponibilidade de uma força de trabalho bem-educada (geralmente no Ocidente) disponível para operações locais e terceirizadas que estão dispostas a trabalhar por salários mais baixos, em relação ao centro, mas que são mais altos em relação aos salários dos outros locais.

O que tornou isso possível foram as inovações - como as tecnologias digitais - que permitem que o trabalho profissional rotineiro (como em saúde, jurídico e educacional) seja realocado (em praças de trabalho de baixo custo), finalizado e devolvido diuturnamente por uma fração do preço. Brown et al. Se referem a esse processo como "taylorismo digital":

Isso envolve traduzir o conhecimento do trabalho de gerentes, profissionais e técnicos em trabalho de conhecimento, capturando, codificando e digitalizando seu trabalho em pacotes de software, modelos e prescrições que podem ser transferidos e manipulados por outras pessoas, independentemente da localização. (...) Diferentemente do taylorismo mecânico, que exigia a concentração do trabalho nas fábricas, o taylorismo digital permite que as atividades de trabalho sejam dispersas e recombinadas de qualquer 
lugar do mundo em menos do tempo do que o necessário para se ler uma frase (Brown et al, 2011: 72).

Esses processos globais de trabalho de produção estão, a propósito, criando uma classe média em países como Índia e China. Esses funcionários, vale notar, “... com educação universitária estão trabalhando em empregos gerenciais e profissionais para empresas transnacionais, sendo exigido, talvez, longas jornadas de trabalho, sentindo constantemente a pressão do cumprimento de árduas metas financeiras; porém, como se fosse vencedores em um leilão global" (Brown et al., 2011: 129).

Um efeito do taylorismo digital na educação é que ele desafia uma base ideológica essencial do contrato social "nacional". Como as economias nacionais agora exercem menos influência na provisão de empregos, elas não podem mais reivindicar a capacidade de fornecer, balizadas na meritocracia, sua promessa de um emprego seguro e salários decentes em troca de autodisciplina, trabalho duro e aprendizado. Esse elo é quebrado e, com ele, um mecanismo essencial de controle social e legitimação para um sistema de estratificação social adequado às economias capitalistas. A globalização da relação capital-trabalho tem, portanto, enormes implicações para os sistemas educacionais nacionais, incluindo a melhor forma de garantir o compromisso contínuo de "fazer bem", quando os retornos são visivelmente escassos para alguns e uma verdadeira cornucópia para um pequeno grupo de outros altamente privilegiados. O sentimento compartilhado mundialmente de que se poderia garantir um compromisso com um projeto social mais amplo e, com ele, formas de coesão social para o Estado, foi rompido. As linhas de fratura e as esperanças desgastadas contribuíram para um powershift que provocou um populismo insurgente e um paradoxal nationalismo endurecedor.

\section{POWERSHIFT4: POPULISMO INSURGENTE / RESSENTIMENTO}

Nas primeiras horas do dia 24 de junho de 2016, podia-se perceber visivelmente o sentido dos votos do Referendo no Reino Unido. Às 04:00, a decisão estava lá para todos verem. O Reino Unido havia votado "SAIR" (Leave) da União Europeia (UE). Depois de meses de acirrado debate entre eurocéticos e eurófilos sobre os benefícios econômicos e políticos a serem obtidos com a saída ou a permanência na EU.

Porém, quando uma decisão tão grandiosa tem a capacidade de mudar o curso de uma nação, não apenas o eixo da Terra mudou, mas também o próprio tecido da vida, fortuna e futuro de grupos inteiros. O primeiro-ministro em exercício, David Cameron, renunciou imediatamente. Almejando a ambição de ser a primeira-ministra do Reino Unido desde a adolescência, Theresa May ocupou o vácuo político, tomando o cetro e, em seu novo papel, pronunciando: "Brexit significa Brexit".

No entanto, foi necessária a eleição de Donald Trump em novembro de 2016 para a Presidência dos EUA, para que todo o peso deste quarto powershift ocorresse. Ao alinhar-se ao 'povo comum', Trump conduziu uma campanha política populista e divisiva que difamava a elite cosmopolita que vive nas cidades e universidades (Fraser, 2017) e que se beneficiaram da globalização. Seja este fenômeno populista nos EUA descrito, conforme Cohen (2019), como sendo de ascensão do populismo autoritário ou, de acordo 
ROBERTSON, S. L.

com Fraser (2017), como sendo de neoliberalismo regressivo; entretanto, ambos, Cohen e Fraser, concordam que é necessário uma análise cultural, política e econômica para compreendermos a ascensão e o apelo da política populista.

Em toda a Europa, Reino Unido e EUA, os perfis de eleitores nos dizem que, de muitas maneiras, foi uma votação feita por aqueles que foram deixados para trás nas corridas da globalização e pela educação, cujos futuros agora pareciam ainda mais sombrios após a crise de 2008 e depois de uma década de políticas de austeridade (Bovens e Wille, 2017; Dorling e Tomlinson, 2019). Como discutido em Powershift 3, a queda de salários, menos oportunidades de trabalho decente e com remuneração adequada e o colapso da promessa de mobilidade social mudaram a vida das pessoas e seus mundos sociais (Streeck, 2014a, 2014b, 2017; Fraser, 2017). Múltiplos déficits democrático, de bem-estar e de status social (Cohen, 2019) - criaram precisamente a nova economia de valor (econômico) e de valores (humanos) - nossos e deles - que poderia e deveria ter sido prevista a partir de décadas de políticas neoliberais e sua política.

Identidades sociais, ressentimento emocional, insegurança econômica, sentimento de irrelevância política e ansiedade de status mobilizam estereótipos enganosos e usam uma política de difamação (Cohen, 2019). Uma nova política de ressentimento é agora visível e palpável, encorajando aqueles que vendiam ódio, especialmente nas mídias sociais. Etno-nacionalismos, racismo e xenofobia são mobilizados e amplificados em um contexto em que a insegurança e a vigilância são o material da vida cotidiana, incluindo a academia.

Embora os desafios enfrentados pelo campo da educação superior sejam claros demais, há um sentimento de desamparo e um sentimento estranho de esperar pela implosão final. Para as universidades do Reino Unido, os fatos econômicos básicos do tema são muito severos. Cerca de $13 \%$ dos estudantes de graduação, $38 \%$ dos pósgraduados e $28 \%$ da equipe acadêmica (professores e técnicos) vêm de fora do Reino Unido. E, não obstante nem todos esses estudantes e acadêmicos sejam da Europa, muitos são.

O setor universitário do Reino Unido é um dos principais beneficiários de fundos de pesquisa da UE - cerca de $£ 0,8$ bilhão de libras esterlinas por ano entram no setor. Com o Reino Unido tomando a dianteira no sentido de de se tornar uma economia competitiva baseada no conhecimento, grande parte do lastro necessário para isto - fundos, cérebros e confiança no futuro - está em risco. O setor universitário não apenas dependia desses mercados de trabalho continentais, mas os estudantes europeus traziam recursos necessários para as universidades, que estavam com cofres minguantes, enquanto as cidades sedes beneficiavam-se com a presença de uma população que trazia recursos para sua manutenção: aluguéis, serviços, alimentação etc. Nos termos do Brexit, os estudantes europeus passariam a pagar como os outros estudantes internacionais, enquanto os candidatos a empregos em universidades do Reino Unido teriam que solicitar vistos de trabalho. Esses desafios econômicos e técnicos são acompanhados por um profundo sentimento de desconforto entre acadêmicos e estudantes em relação ao status de migrantes e às novas políticas de ressentimento. O que havia sido uma Europa em expansão estava agora sendo redefinida para reverter a marcha, com a própria Europa enfrentando uma nova onda de nacionalismos e uma intensificação das políticas de medo, exclusão, recolocação de fronteiras e ressentimento (Yuval-Davis, 2018). 
É claro que o regionalismo europeu e o papel da educação superior estão enfrentando novos desafios neste momento (Robertson et al, 2016). Este powershift tem a força de um abalo sísmico e os ventos da mudança continuam soprando, seu turbilhão se entrança aqui e acolá, à medida que a impossibilidade de cumprir a tarefa [de integração plena] e a incerteza do futuro são confrontadas diariamente.

\section{SOBRE O QUE DEVE SER FEITO}

Comecei este capítulo com referência ao trabalho de Toffler (1991) e seu argumento de que o fim da guerra fria implicaria em um powershift na ordem mundial. Trajetórias de desenvolvimento e o arco do tempo não são lineares. As dobras também não se desenrolam de maneira inevitável, embora claramente existam dependências de caminhos que moldam desdobramentos de maneiras estruturantes, bem como conjuntos de contradições que preparam as sementes para mudanças contínuas.

Faço esse argumento para lembrar o papel que os atores sociais acadêmicos devem desempenhar nesta época, estimulando debates, desafiando práticas, propondo novas alternativas e desenvolvendo e incorporando novas atitudes. Precisamos desafiar o excesso de individualismo e competição, o "cercamento" de conhecimentos, as práticas de vigilância, o medo do outro e a liberdade acadêmica limitada, que agora define a academia contemporânea. Nosso desejo de reconhecimento e respeito, quando pressionado pelo peso da vitória a qualquer custo, instiga a culpa e o ressentimento.

No entanto, precisamos mais do que palavras. Se quisermos superar essas diferenças sociais, étnicas e educacionais, a educação superior precisa ser repensada não apenas em termos sociais, culturais e políticos mais amplos, mas também de maneiras que incluam o envolvimento ativo com uma série de movimentos sociais cada vez mais engajados por uma nova geração de jovens que estão corretamente fazendo exigências. Como seria um quinto e um sexto powershift que não tenha se repetido nos últimos trinta anos? O que seria necessário em nossas próprias instituições de educação superior para afastar-se do neoliberalismo regressivo? Uma coisa está clara. Nossa análise também precisa levar em conta não apenas a dinâmica do capital e do estado, e as maneiras pelas quais os mundos da vida e as visões de mundo são moldados e vividos, mas uma reflexão sobre o que pode ser feito de maneira que valorizem a igualdade e a fraternidade e não simplesmente a liberdade. Quais decisões e ações políticas queremos que criem condições para a produção de indivíduos críticos e de mente aberta, que valorizem mais do que difamem aqueles cujas fortunas e futuros são no final do dia não muito diferentes dos seus? Se houver algo aviltante, deve ser encotrado na natureza do capitalismo sem peias, nas formas do novo imperialismo e naqueles que foram indecorasamente beneficiados pelo sistema. 


\section{POWERSHIFTS IN THE POWER HOUSES: EUROPE, HIGHER EDUCATION AND THE SEISMIC WINDS OF CHANGE}

ABSTRACT: This article aims to analyze the dynamics of powershifts, including that caused by the Brexit process since the 2016 referendum, and its social, political and economic consequences for society and higher education in the United Kingdom and Europe.

\section{CAMBIOS DE PODER EN LA CASA DE LAS FUERZAS: EUROPA, EDUCACIÓN SUPERIOR Y ONDAS SÍSMICAS DE DESPLAZAMIENTO}

RESUMEN: Este artículo tiene como objetivo analizar las dinámicas de los cambios de poder, incluida la causada por el proceso Brexit desde el referéndum de 2016, y sus consecuencias sociales, políticas y económicas para la sociedad y la educación superior en el Reino Unido y Europa.

\section{NOTAS}

1) Segundo o Cambridge Dictionary, Brexit é definitido como "an exit (= act of leaving) by the United Kingdom from the European Union (short for "British exit")" Tradução: "saída (= ato de deixar) do Reino Unido da União Europeia (abreviação de "British exit")].

2) Nota dos tradutores: A frase "uma maré cheia levanta todos os barcos" (A rising tide lifts all boats) está associada aos defensores do livre-mercado que, ideologicamente, afirmam que a melhora econômica de um País (região), especialmente diminuindo a tributação sobre os riscos, beneficia a todos que estão no mesmo barco (independentemente de sua renda: dos ricos aos pobres).

3) Por exemplo, o Departamento de Comércio da Comissão Europeia foi o único negociador em nome de todos os seus países membros. Como resultado, o Reino Unido tinha muito pouco conhecimento especializado em negociação comercial em seus departamentos governamentais.

4) Com exceção da Escócia, no Reino Unido, a maioria dos eleitores que votaram no Referendo para permanecer tinha níveis mais altos de qualificação educacional, enquanto que aqueles que votaram em "deixar", majoritariamente, apresentavam níveis mais baixos de qualificação educacional.

5) No Brasil, o livro foi de Alvin Toffler foi publicado, em 1991, pela Editora Record com o título: Powershift - As Mudanças do Poder.

6) Nota dos tradutores: Powershift pode ser traduzido como "deslocamento de poder" ou "mudança de poder"; entretanto, por se tratar de uma expressão constante no título do livro de Toffler, que inspira este artigo, preferimos manter-se a expressão no idioma original.

7) Note-se que o País de Gales e a Escócia têm, para a educação superior, políticas e estruturas de taxas (anuidades) diferentes em comparação à Inglaterra.

8) A justificativa para o aumento do ônus para os alunos era que a obtenção de um diploma gerava um aumento significativo no salário (prêmio pela graduação) de mais de $£ 100.000$ libras ao longo da vida. No entanto, tratar estes valores pela média não permite perceber a evidência de que algumas profissões (como medicina, direito, odontologia e gestão de negócios) geram retornos significativos que distorcem a média. Os alunos matriculados em áreas como as artes e humanidades tendem a ganhar significativamente menos que isso ao longo da vida.

9) Nota dos tradutores: FTSE 100 - Financial Times Stock Exchange 100 Index - Representa um grupo 100 empresas de capital aberto com ações negociadas na Bolsa de Valores de Londres. 
10) Havia 51.930 estudantes de graduação em cursos oferecidos por provedores alternativos (PAs) em 2016/17. Desses, 25.785 estavam no primeiro ano de estudo (HESA, 2019).

\section{REFERÊNCIAS}

Ali, T., (2003) Re-colonizing Iraq, New left Review, 21, May-June, pp. 5-19.

Ali, T., (2008) Afghanistan: mirage of the good war, New left Review, 50, March April, pp. 5-22.

Arrighi, G. (1994) The Long Twentieth Century: Money, Power and the Origins of Our Times, London: Verso.

Beckert, J., (2014) Imagined Futures, Cambridge: Harvard University Press.

Bernstein, B., (2000) Pedagogy, Symbolic Control and Identity, London: Rowan and Littlefield.

BIS (2009) Higher Ambitions: the Future of Universities in a Knowledge Economy, BIS: London.

Brown, R. (2011) The new English quality assurance regime, Quality in Higher Education, 17 (2), pp. 213-229.

Browne, J. (2010) Securing a Sustainable Future for Higher Education: An Independent Review of Higher Education Funding and Student Finance, London, BIS

Bovens, M. and Wille, A., (2017) Diploma Democracy: the Rise of Political Meritocracy, Oxford: Oxford University Press.

Castells, M. (1996) The Rise of the Network Society, London: Blackwell.

Cohen, J., (2019) Populism and the Politics of Resentment, Jus Cogen: A Critical Journal of the Philosophy of Law and Politics, January.

Crouch, C. (2011) Strange Non-Death of Neoliberalism. Cambridge: Polity.

Dorling, D., and Tomlinson, S., (2019) Rule Britannia, London: Biteback Publishing.

Eco, U. (2013), Inventing the Enemy, London: Vintage Books.

Fisher, J. (2015). Nobel Laureate Joseph Stiglitz: ere is No Magic Bullet to Fix Income Inequality." Business Insider UK. May 6th. Accessed June 18. http://uk.businessinsider.com/nobel-laureate-joseph-stiglitz-2015-4 
ROBERTSON, S. L.

Foray, D., (2004) The Economics of Knowledge, Boston: MIT Press

Fourcade, M. (2016). Ordinalization: Lewis A Coser Memorial Award for Theoretical Agenda Setting, Sociological Theory, 34 (3), pp. 175-195.

Fraser, N. (2017) From Progressive Neoliberalism to Trump and Beyond, America Affairs, 1 (4), accessed on $7^{\text {th }}$ February at https://americanaffairsjournal.org/2017/11/progressive-neoliberalism-trump-beyond/

Glees, A., and Pope. C. (2005) When Students Turn to Terror: Terrorist and Extremist Activity on British Campuses, London: The Social Affairs Unit.

Green, J., and Hay, C., (2015) Toward a new political economy of the crisis: getting what went wrong right, New Political Economy, 20 (3), pp. 331-341.

Harvey, D. (1989) The Condition of Postmodernity, Oxford: Blackwell.

Harvey, D. (2003) The New Imperialism, Oxford: Oxford University Press.

Harvey, D. (2005). A Brief History of Neoliberalism, Oxford University Press: Oxford.

Harvey, D., (2004) Seventeen Contradictions and the End of Capitalism, London: Profile Books.

Heath-Kelly, C. (2013) Counter-Terrorism and the counterfactual: producing the 'radicalisation' discourse and the UK Prevent Strategy, British Journal of Politics and International Relations, 15, pp. 394-415.

HEFCE (2017) Framework for the Monitoring of the Prevent Duty in Higher Education in England, Bristol: HEFCE.

Hettne, B., and Söderbaum, F., (2000) Theorising the rise of regionness, New Political Economy, 5 (3), pp. 457-72.

HESA (2019) Higher Education Statistics: Alternative Providers. Accessed $28^{\text {th }}$ February, 2019 - https://www.hesa.ac.uk/news/15-02-2018/sfr249-higher-education-studentstatistics-APs

Hobsbawm, E. (1994) Age of Extremes: The Short Twentieth Century 1914-1991, London: Abacus.

Holland, K. 2015. The High Economic and Social Costs of Student Loan Debt. CNBC News, 15 June. Accessed June 18 ${ }^{\text {th }}$ 2015. http://www.cnbc.com/id/102742696 
Jessop, B. (1999). The changing governance of welfare: recent trends in its primary functions, scale and modes of coordination, Social Policy and Administration, 343 (4), pp. 348-59.

Kotz, D., (2018) End of the neoliberal era? Crisis and restructuring in American capitalism, New Left review, 113, September-October, pp. 29-55

Leys, C. (2003) Market-Driven Politics: Neoliberal Democracy and the Public Interest, London: Verso.

Lundvall, B-A., and Johnson, B., (1994) The learning economy, Journal of Industry Studies, 1 (2), pp. 23-42.

McGettigan, A. (2012) False Accounting: Why the government's Higher Education reforms don't add up, London: Intergenerational Foundation.

Monahan, A. and Wiele, S., (2017) UK student loan debt soars. Guardian, accessed on $7^{\text {th }}$ February, 2019 at https://www.theguardian.com/money/2017/jun/15/uk-student-loandebt-soars-to-more-than-100bn

Newfeld, C. (2010). The Structure and the Silence of the Cognitariat, Globalisation, Societies and Education 8 (2): 175-189.

OECD. (2014). Does Income Inequality Hurt Economic Growth? Paris: OECD.

Peck, J. (2010) Constructions of Neoliberal Reason, Oxford: Oxford University Press.

Piketty (2014) Capital in the Twenty First Century, Cambridge, USA: Belnap/Harvard.

Robertson, S.L. (2009) 'Producing' the Global Knowledge Economy: the World Bank, the KAM, Education and Development, in M. Simons, M. Olssen and M. Peters (eds) Rereading Education Policies: Studying the Policy Agenda of the 21stCentury, Rotterdam: Sense Publishers.

Robertson, S. Bonal, X and Dale, R. (2002) GATS and the Education Service Industry, Comparative Education Review, 46 (4), pp. 472-96.

Robertson, S. and Keeling, R. (2008) Stirring the lions: strategies and tactics in global higher education. Globalisation, Societies, and Education, 6, (3), pp. 221-240.

Robertson, S. Olds, K., Dale, R., and Dang, Q-A., (2016) Global Regionalisms and Higher Education, Cheltenham: Edward Elgar. 
ROBERTSON, S. L.

Robertson, S. and Kedzierski, M. (2016) On the move: globalising higher education in Europe and beyond, The Language Learning Journal, 44:3, 276-291

Saeed, T., and Johnson, D., (2016). Intelligence, global terrorism and higher education: neutralising threats or alienating enemies, British Journal of Educational Studies, 64 (1), pp. 37-51.

Sayer, A., (2011) Why Things Matter to People, Cambridge: Cambridge University Press.

Seabrooke, L. and Bowden, B., (2004) Golden Standards and the Making of Market Civilisation, London and New York: Routlege.

Sennett, R., (2006) The Culture of the New Capitalism, New Have: Yale.

Slater, D. and Tonkiss, F. (2001) Market Society, Cambridge: Polity

Stein, B. 2006. Class Warfare, Guess Which Class is Winning, New York Times, Nov. 26. Accessed June 18, 2015, http://www.nytimes.com/2006/11/26/business/yourmoney/26every.html?_r=0.

Streeck, W. (2014a) How Will Capitalism End?" New Left Review 87, May/June: 35-64.

Streeck, W. (2014b). Buying Time: The Delayed Crisis of Democratic Capitalism. London and New York: Verso.

Streeck, W., (2017) The return of the repressed, New Left Review, 104, March-April, pp.518.

Toffler, A. (1991) Powershift, New York. Bantam Books

UNESCO (2005a) Towards Knowledge Societies, Paris: UNESCO.

UUK, (2016) Submission of written evidence from Universities UK to the House of Commons Education Inquiry on The Impact of Exiting the European Union on higher Education, London: UUK.

Yuval-Davis, N., (2018) Contemporary politics of belonging and everyday bordering, in M. Schulz (ed.) Frontiers of Global Sociology, Berlin: ISA Research. 
SUSAN L. RoberTSOn: PhD (Sociology/Policy) University of Calgary, Canada. B.Ed (Honours) University of Western Australia, Australia. B Applied Science (Distinction) Curtin University. Currently teaches at Postgraduate in Faculty of Education of University of Cambridge: Masters in Globalisation, Education and International Development, Supervision of Masters and Doctoral candidates.

Orcid: https://orcid.org/0000-0002-6757-8718

E-mail: slr69@cam.ac.uk

Este periódico utiliza a licença Creative Commons Attribution 3.0, para periódicos de acesso aberto (Open Archives Iniciative - OAI). 